\title{
A ball thrombus in the left ventricle in association with Sweet syndrome
}

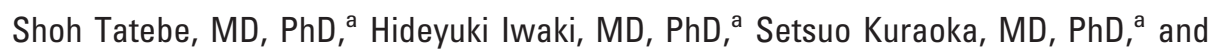

Shigeruko lijima, MD, PhD, ${ }^{\text {b }}$ Mito City, Japan

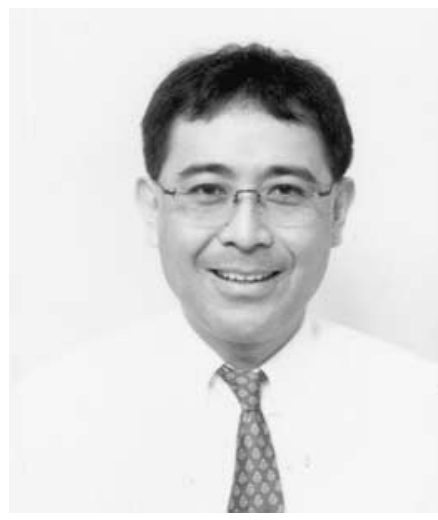

Dr. Tatebe

$\mathrm{I}$ ntracardiac thrombus, particularly in the left side of the heart, raises the concern of thromboembolism, which can result in sudden death. ${ }^{1}$ Apart from mural thrombus in patients with ischemic heart disease, thrombi are rarely encountered in the left ventricle (LV), and they are common in the left atrium. We describe a rare case of ball thrombus in the LV, which was successfully excised. The patient had no history of ischemic heart disease or valvular disease and had a normal sinus rhythm. The patient's postoperative period was complicated by a systemic inflammatory disease, namely Sweet syndrome. ${ }^{2} \mathrm{We}$ present a brief review of ball thrombus in the $\mathrm{LV}$, as well as a discussion regarding its atypical association with Sweet syndrome in this case.

\section{Clinical Summary}

A 67-year-old man had a high temperature $\left(>39^{\circ} \mathrm{C}\right)$, together with itchy skin and a macular rash on his body. He had these symptoms for 3 months. His medical history included only an appendectomy 6 years previously; no heart attacks were noted. On physical examination, a grade $2 / 6$ systolic murmur was heard at the apex of the heart. There were no signs suggestive of ischemic heart disease or congestive heart failure. The electrocardiogram showed a normal sinus rhythm without changes related to ischemic heart disease. Transthoracic echocardiography revealed a floating mass in the LV and mild mitral regurgitation (Figure 1), despite good biventricular function. The mass was $3 \mathrm{~cm}$ in diameter and sus-

From the Departments of Thoracic and Cardiovascular Surgerya and Der-

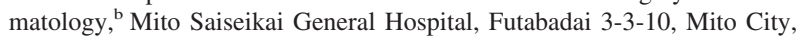
311-4198, Japan.

Received for publication March 1, 2002; accepted for publication March 29, 2002.

Address for reprints: Shoh Tatebe, MD, PhD, Department of Thoracic and Cardiovascular Surgery, Niigata University Graduate School of Medicine, 757 Asahimachi-Dohri 1, Niigata City, 951-8510, Japan.

J Thorac Cardiovasc Surg 2003;125:209-11

Copyright $\odot 2003$ by The American Association for Thoracic Surgery $0022-5223 / 2003 \$ 30.00+0$

doi: $10.1067 / \mathrm{mtc} .2003 .120$ pended by tendons from both the anterior mitral leaflet and the anterior papillary muscle. Complete blood counts showed mild anemia, whereas clotting test results, including prothrombin test results, activated partial thromboplastin times, fibrinogen levels, antithrombin III levels, D-dimer levels, and fibrin-degenerated products were within normal limits. Liver function test results were increased, and other laboratory examinations were as follows: C-reactive protein, $10.8 \mathrm{mg} / \mathrm{dL}$; rheumatoid factor, $10 \mathrm{U} / \mathrm{mL}$; antistreptolysin-O, $286 \mathrm{U} / \mathrm{mL}$; and interleukin $6,12.7 \mathrm{pg} / \mathrm{mL}$. The possibility of imminent thromboembolism and sudden death, as well as the concern of infective endocarditis, led to an urgent surgical removal of the tumor. The operation was performed through a median sternotomy by using standard cardiopulmonary bypass. After clamping the aorta, the heart was arrested by means of cardioplegic solution, and the left atrial cavity was explored by opening the fossa ovalis. An encapsulated mass, measuring $3.0 \times$ $3.0 \times 2.5 \mathrm{~cm}$, was seen through the mitral orifice (Figure 2) and excised. The attachment to the anterior mitral leaflet was sliced and then reapproximated by using interrupted 6-0 polypropylene sutures. Coaptation of the mitral valve was tested by infusing saline solution into the LV cavity; this test confirmed no regurgitation. The cardiopulmonary bypass successfully came off with small doses of inotropic agents. Microscopically, the mass was filled with fibrin and red cells, which was compatible with the findings of thrombus. No inflammatory cells had infiltrated into the thrombus and the capsule.

The patient's postoperative course was uneventful until 15 days after the operation, when he became ill, with a high temperature of more than $39^{\circ} \mathrm{C}$ and macular skin rashes, and presented with an increased liver function test result. This was the identical clinical picture he had previously. He was started on intravenous antibiotics, which failed to improve his symptoms. He was then referred to the dermatology service, which diagnosed Sweet syndrome (acute neutrophilic febrile dermatosis). The diagnosis was confirmed by means of skin biopsy. An anti-inflammatory agent, naproxen, was started, after which the patient's condition dramatically improved. Corticosteroids were not used. Scores of blood samples were taken and sent for culture, and no organisms were grown. Clinical work-up for inflammatory bowel disease and hematopoietic neoplasm were performed and found to be negative. 


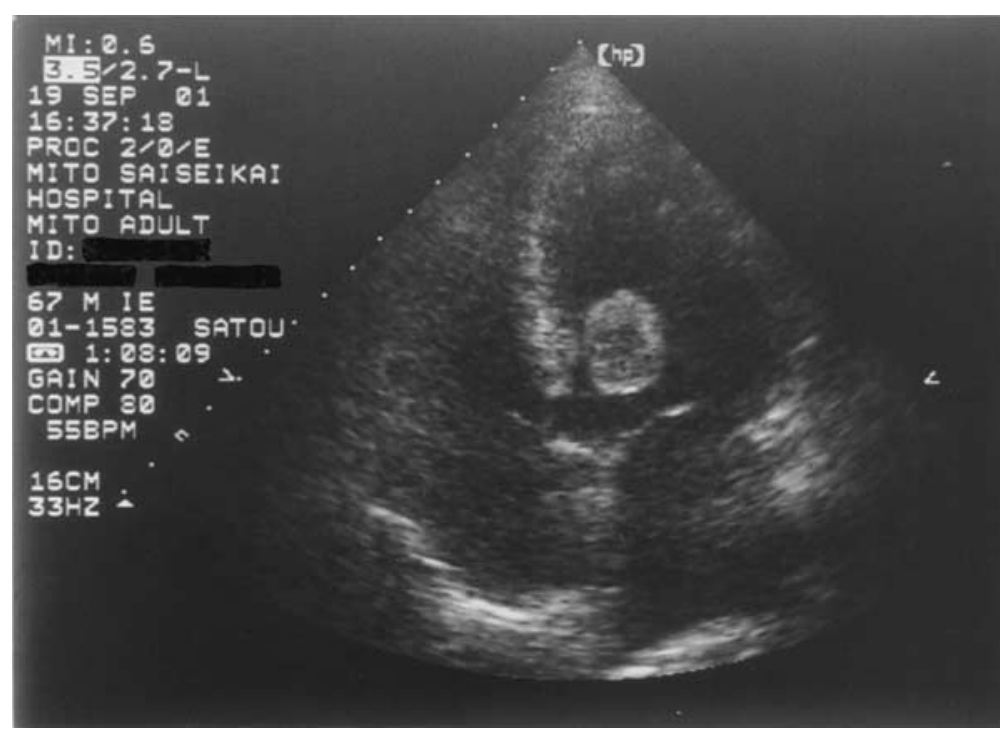

Figure 1. Preoperative echocardiography: long-axis view from the apex. A ball-like mass floats in the LV.

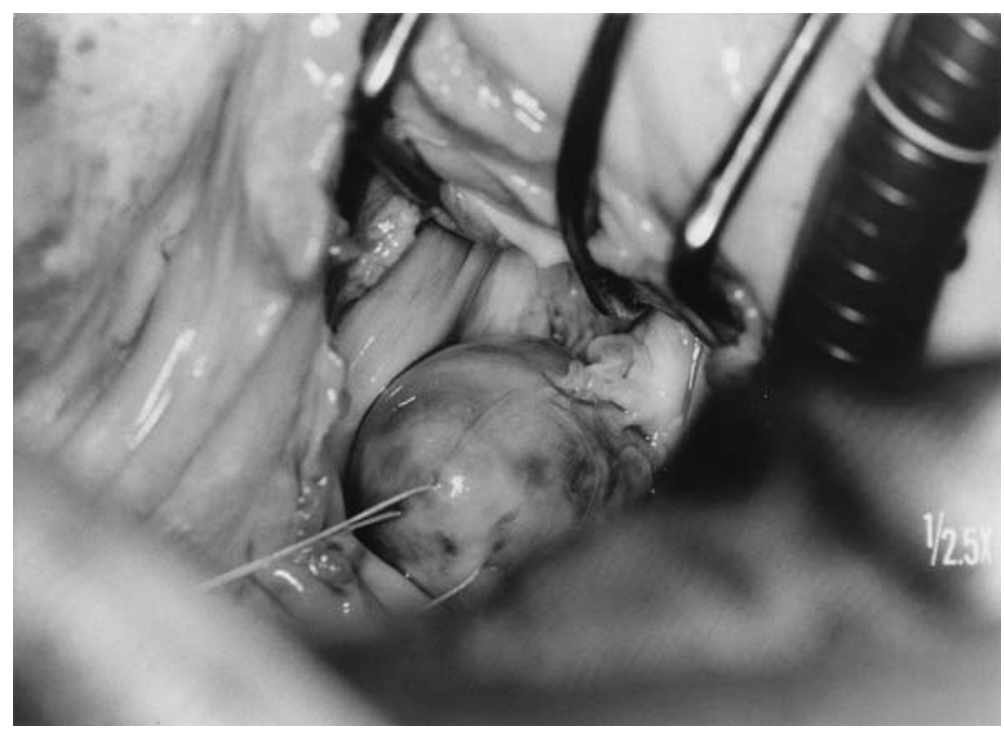

Figure 2. Intraoperative photograph: surgeon's view. A mass is seen through the mitral valve orifice.

\section{Discussion}

Intracardiac thrombus in the LV is not so uncommon in patients with certain cardiac diseases, such as ischemic heart disease. The incidence of impaired LV contractility in cases of myocardial infarction has been reported as $8.9 \% .^{3}$ In our patient there was no history of myocardial infarction and no evidence of rheumatic valvular disease; atrial fibrillation was ruled out as well. Furthermore, most cases of thrombus in the LV are mural thrombi and not ball thrombi. Therefore, this case is a rare presentation of LV thrombus. The thrombus was suspended by chordae tendineae from both the mitral valve and the papillary muscle. Paloheimo ${ }^{4}$ reported an unusual presentation of thrombus, which he supposed had grown along a threadlike strand from the right atrium to the right ventricle. We cannot clarify the pathogenesis in our case because the ball thrombus was actually in the LV and not in the right ventricle. However, a similar mechanism is suggested; that is the thrombus seemed to have grown along the chordae tendineae of the mitral valve.

In addition to the rarity of ball thrombus in the $\mathrm{LV}$, this case was complicated by a systemic inflammatory disease, namely Sweet syndrome. Sweet ${ }^{2}$ first described the condition characterized by the sudden onset of fever, leukocytosis, and cutaneous eruption. The eruption consists of tender, erythematous, welldemarcated papules and plaques that show dense neutrophilic infiltrates microscopically. This condition involves oral mucosa, joints (arthralgia), eye, lungs, kidney, liver, bone, and the central nervous system. ${ }^{5}$ Our patient had high fever, anemia, and skin lesions. Despite complete blood count showing no leukocytosis, a skin biopsy confirmed infiltration of neutrophils, which was compatible with the findings of Sweet syndrome. The pathogenesis of 
Sweet syndrome is still unknown; however, it is presumed to be a type of hypersensitivity reaction that leads to stimulation of a cascade of cytokines that precipitate neutrophil activation and infiltration. ${ }^{5}$ That is why corticosteroids and immunosuppressants have been successfully used as treatments. ${ }^{6}$ We chose a nonsteroidal antiinflammatory agent over a corticosteroid or immunosuppressant.

The most frequent conditions associated with Sweet syndrome are inflammatory bowel disease and hematopoietic neoplasm. ${ }^{5} \mathrm{~A}$ work-up revealed that the patient did not have these diseases. Cardiovascular involvement in Sweet syndrome is not so common. There are a few reports of cardiovascular involvement in patients with Sweet syndrome. ${ }^{7}$ Hayashi and associates ${ }^{8}$ reported a female patient with Sweet syndrome who underwent aortic and mitral valve replacement; this patient's native valves showed no neutrophil infiltration. Similarly, no inflammatory cells had infiltrated either the capsule or thrombus of our patient. We cannot find any definite relationship between LV thrombus and Sweet syndrome, and therefore we suggest that this is a case in which LV thrombus and Sweet syndrome simply coincided.

\section{References}

1. Wohlfarter T, Hopferwieser T, Schwaighofer H, Knapp E, Lechleitner M, Kunz F, et al. An idiopathic floating left-ventricular thrombus. Dtsch Med Wochenschr. 1991;116:808-11.

2. Sweet RD. An acute febrile neutrophilic dermatosis. Br J Dermatol. 1964;139:349-53.

3. Beppu S, Park Y-D, Sakakibara H, Nagata S, Nimura Y. Clinical features of intracardiac thrombosis based on echocardiographic observation. Jpn Circ J. 1984;48:75-82.

4. Paloheimo JA. Thread-like strand from right atrium into right ventricle as leader of freely moving ball thrombus. Br Heart J. 1973;35:223-5.

5. von den Driesch P. Sweet's syndrome. J Am Acad Dermatol. 1994; 31:535-56.

6. von den Driesch P, Steffan C, Zobe A, Hornstein OP. Sweet's syndrome: therapy with cyclosporine. Clin Exp Dermatol. 1994; 19:274-7.

7. Guia JM, Frias J, Castro FJ, Gracián M. Cardiovascular involvement in a boy with Sweet's syndrome. Pediatr Cardiol. 1999;20:295-7.

8. Hayashi I, Hosoda Y, Kawasaki S, Yamamoto T, Dohi S, Kawai S. Aortic and mitral valve replacement in a patient with acute febrile neutrophilic dermatosis (Sweet's syndrome): report a case. Surg Today. 2001;31:810-3.

\title{
Apolipoprotein E4 increases aortic atheroma burden in cardiac surgical patients
}

\author{
Lian K. Ti, MMed, G. Burkhard Mackensen, MD, Hilary P. Grocott, MD, FRCPC, Daniel T. Laskowitz, MD, \\ Barbara G. Phillips-Bute, PhD, Carmelo A. Milano, MD, Andrew K. Hilton, MB, BS, FANZCA, Mark F. Newman, MD, \\ Joseph P. Mathew, MD, and the Neurologic Outcome Research Group, Durham, NC
}

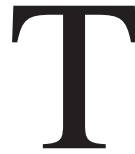
he increasing numbers of elderly patients undergoing cardiac surgery emphasizes the importance of identifying risk factors associated with adverse neurologic outcomes. Although the apolipoprotein $\epsilon 4$ allele $\left(A P O E^{*} E 4\right)$ has been identified as a risk factor, ${ }^{1}$ how its presence increases neurologic risk remains uncertain. Apolipoprotein $\mathrm{E}$ (ApoE) plays a key role in lipoprotein metabolism and has an important influence on the pathophysiology of atherosclerosis. ApoE's 3 major alleles $\left(A P O E^{*} E 2, A P O E^{*} E 3\right.$, and $\left.A P O E^{*} E 4\right)$

\footnotetext{
From the Divisions of Cardiothoracic Anesthesiology and Critical Care, Cardiovascular and Thoracic Surgery, and Neurology, Departments of Anesthesiology, Surgery, and Medicine, Duke University Medical Center, Durham, NC.

Supported in part by grants from National Institutes of Health (NIH) grant 1R01HL54316, Clinical Research Centers Program NIH MO1-RR-30, and American Heart Association Grant-In-Aid 95010970.

Received for publication Sept 3, 2001; accepted for publication May 22, 2002.

Address for reprints: Joseph P. Mathew, MD, Box 3094, Duke University Medical Center, Durham, NC 27710 (E-mail: mathe014@mc.duke.edu).

J Thorac Cardiovasc Surg 2003;125:211-3

Copyright $\odot 2003$ by The American Association for Thoracic Surgery

$0022-5223 / 2003 \$ 30.00+0$

doi: $10.1067 / \mathrm{mtc} .2003 .123$
}

result in differing susceptibility to dyslipidemia, atherosclerosis, and coronary heart disease. Therefore we sought to determine whether the $A P O E^{*} E 4$ allele influences aortic atheroma burden in patients undergoing cardiac surgery.

\section{Patients and Methods}

With institutional review board approval, a comprehensive transesophageal echocardiography examination was performed in 128 patients undergoing coronary artery bypass grafting surgery. For analysis, a videotaped frame displaying the most diseased area in each aortic segment was digitized. By tracing the outline of the atheroma, the area subtended by the atheroma was estimated (area of plaque). Similarly, the area of visualized aorta in the ascending aorta and aortic arch was measured by tracing the visualized segment of the aorta (Figure 1). The area of the visualized aorta in the descending aorta was measured by estimating the angle $(\alpha)$ subtended by the vessel wall and calculated as a portion of a circular or complete vessel $\left(\pi r^{2} \cdot \alpha / 360^{\circ}\right.$; Figure 1). Atheroma burden in each segment was then calculated as the percentage of area of the visualized aorta containing atheroma. Genomic DNA was used to determine $A P O E$ allele frequencies, as previously described. ${ }^{2}$ Differences between patients with and without the $A P O E^{*} E 4$ allele were compared by using the Wilcoxon rank sum test and the Fisher exact test. The association of atheroma burden and genotype was investigated with multivariable linear regression controlling for age, sex, and diabetes. 